\title{
Preparation and characterization of nanocomposites of natural rubber with polystyrene and styrene-methacrylic acid copolymer nanoparticles
}

\author{
P. Chaiyasat, C. Suksawad, T. Nuruk, A. Chaiyasat* \\ Department of Chemistry, Faculty of Science and Technology, Rajamangala University of Technology Thanyaburi, \\ Klong 6, Thanyaburi, 12110 Pathumthani, Thailand
}

Received 5 November 2011; accepted in revised form 16 January 2012

\begin{abstract}
Composites of natural rubber (NR)/vinyl polymer nanoparticles as polystyrene (PS) and poly(styrenemethacrylic acid) (P(S-MAA)) were prepared by heterocoagulation technique. The polymer nanoparticles were prepared by emulsifier-free emulsion polymerizations at $70^{\circ} \mathrm{C}$ using potassium persulfate as initiator. Under acidic condition where positive charge was present on the NR latex (NRL) surface, the nanoparticles having negative charge mainly from sulfate group of initiator were able to adsorb on the NRL surface, the electrostatic interaction being the driving force. The scanning electron micrographs showed that the polymer nanoparticles are homogenously distributed throughout NR matrix as nanoclusters with an average size of about 500 and $200 \mathrm{~nm}$ for PS and P(S-MAA), respectively. The mechanical properties of NR/PS and NR/P(S-MAA) composite films were compared with the NR host. The nanocomposites, particularly when the polymer nanoparticles are uniformly dispersed, possess significantly enhanced mechanical properties strongly depending on the morphology of the nanocomposites.
\end{abstract}

Keywords: nanocomposites, heterocoagulation, natural rubber latex

\section{Introduction}

Natural rubber (NR, Figure 1a) is one of the most important polymers characterized by excellent elasticity and flexibility, which is widely used in various applications such as medical glove and tubing [1-3]. Because of unsaturated bonds in its macromolecular backbone, it is weak in oil and ozoneresistance due to oxidative or thermal degradation. Thus, short shelf lives and life cycles may be obtained from such NR products. To overcome these drawbacks, some chemical substances was used to treat NR such as tris(nonylated phenyl) phosphate [4] and non-water-soluble amino acids [5]. Moreover, loss of mechanical properties such as low tensile strength and poor tear resistance are also the drawbacks of NR. Many techniques were investi- gated in order to improve such disadvantages of NR without reducing its wonderful properties. The concept of nano-matrix-dispersed polymer was applied using a small amount of functional polymer polymerized on NR latex (NRL) and then forming matrix. The nano-matrix-dispersed polymer may be prepared by graft copolymerization of natural rubber in latex form. However, side reactions during the graft copolymerization were obtained due to the presence of proteins on the NRL surface [6]. Thus, removal of the protein before graft copolymerization of NR to prepare nano-matrix was carried out [1]. In addition, the conventional reinforcement by adding inorganic materials such as carbon black [7], ultra-fine calcium carbonate [8] and modified montmorillonite [9] were used to strengthen NR. How-

\footnotetext{
${ }^{*}$ Corresponding author, e-mail: a chaiyasat@mail.rmutt.ac.th
} (c) BME-PT 


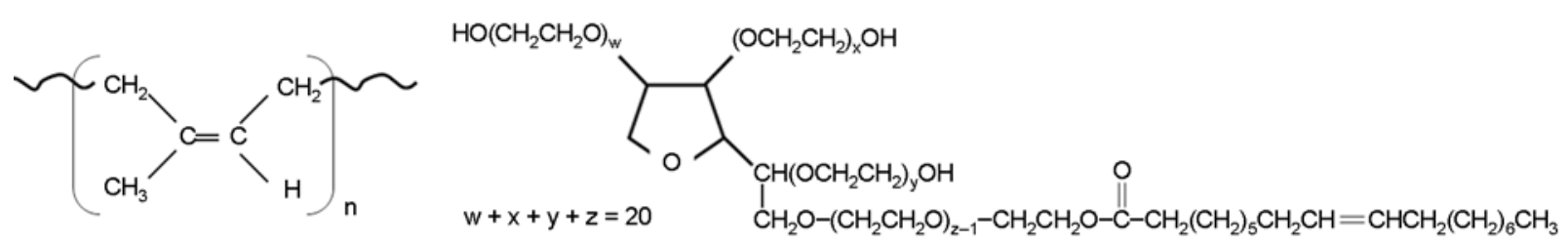

a)

b)

Figure 1. Structure of NR (a) and tween 80 (b)

ever, they have low efficiency to improve NR properties due to the increasing of the compound density or reducing light transmission. Alternative reinforcement such as nano-fillers have recently attracted attention because using only low amount of nanofillers can maintain and control the beneficial properties of NR (flexibility, toughness and etc.) and the fillers (hardness, thermal stability and etc.). Clay minerals are useful to reinforce NR via well-known techniques as melt processing $[10,11]$, latex-compounding [12] and solution-mixing methods [13]. Moreover, mechanical properties of polymer composite of NR are also improved using nano crab chitin whiskers [14] and surface modified nanocrystalline cellulose [15].

Heterocoagulation is the common interaction of two particles, small and large particles, of a dissimilar nature upon collision. The smaller particles adsorb onto the larger particle surface with various forces such as electrostatic, hydrophobic and secondary molecular interactions as (multiple) hydrogen bonding [16]. This technique is interesting to prepare polymer composite because the polymers are directly blended in emulsion state which would consume less energy and time without grinding. Generally, it is used to prepare polymer composite such as inorganic-inorganic [17], inorganic-organic $[3,18]$ and organic-organic [19-23] composites. Moreover, to improve NR properties, nanocomposites including NR and inorganic or polymer nanoparticles have been prepared by this technique. The oil resistance of NR film was improved by using small organic particle, polychloroprene (CR), adsorbed onto large NR particle with the heterocoagulation technique [24]. CR would adsorb onto the NR particle surface via hydrogen bonding between carboxylic groups of the protein molecules existing on the NR surface and the polyethylene oxide chains of Tween 80 adsorbed on the CR particles. In addition, the mechanical properties of NR were improved with inorganic particle as $\mathrm{SiO}_{2}$ nanoparti- cles [3]. $\mathrm{SiO}_{2}$ nanoparticles having negative charge on their surfaces were pre-adsorbed with positively charged poly (diallyldimethylammonium chloride) chain before heterocoagulation with NR particle having negative charge of protein existing on the NR surface.

In this work, the simple blending of NRL with polymer nanoparticles using heterocoagulation technique without using any pre-polymer is studied. NRL emulsion is added with a small amount of hard polymer nanoparticles emulsion of polystyrene (PS) or poly(styrene-methacrylic acid) (P(S-MAA)). The nanoparticles having negative charge deriving from initiator adsorbed on NRL surface containing protein-lipid via electrostatic interaction to form composite polymer at the appropriate $\mathrm{pH}$. The mechanical properties of the obtained composite polymer may improve.

\section{Experimental \\ 2.1. Materials}

Styrene (S) (Aldrich, Wisconsin, USA; purity, 99\%) was purified by pass through the column packed with basic Aluminium oxide. Methacrylic acid (MAA) (Merck, Munich, Germany; purity, 99\%) was purified by distillation under reduced pressure in a nitrogen atmosphere. The purified monomers were stored in a refrigerator. Potassium persulfate (KPS; Aldrich, Wisconsin, USA) was purified by recrystallization. High ammonia NR latex (ca. 60\% dry rubber content; donated from Thai Rubber Latex Co., Ltd., Bangkok, Thailand) was used as received. Analytical grade of sodium hydroxide $(\mathrm{NaOH} ; \mathrm{BDH}$ Prolabo, Leuven, Belgium) and hydrochloric acid ( $\mathrm{HCl}$; Ajax Finechem Pty. Ltd., Sydney, Australia) were used as received. Polyoxyethylene (20) sorbitan monooleate (Tween 80; Aldrich, Wisconsin, USA; Figure 1b) was used as received. Deionized water with a specific resistance of $5 \cdot 10^{6} \Omega \cdot \mathrm{cm}$ was distilled before used. 


\subsection{Polymer nanocomposites preparation}

The polymer nanoparticles were prepared by emulsifier-free emulsion polymerization under the conditions listed in Table 1 . The polymerizations were carried out at $70^{\circ} \mathrm{C}$ with a stirring rate of $200 \mathrm{rpm}$. The monomer (30 and $10 \mathrm{~g}$ for P(S-MAA) and PS, respectively) and water (250 and $270 \mathrm{~g}$ for $\mathrm{P}(\mathrm{S}$ MAA) and PS polymerization, respectively) were charged into the reactors and then purged with $\mathrm{N}_{2}$ for $30 \mathrm{~min}$. The polymerizations were initiated by the addition ( $20 \mathrm{~g}$ ) of KPS aqueous solution (1.2 $\mathrm{wt} \%)$. The nanocomposites of NR/PS and NR/P(S-MAA) were prepared with heterocoagulation technique (Figure 2) according to the following procedures. The $\mathrm{pH}$ of NRL aqueous dispersion (solid content about $10 \mathrm{wt} \%$ ) containing Tween 80 emulsifier ( $6 \mathrm{wt} \%$ of NR) was adjusted from approximately 11 to 7 with $0.3 \mathrm{M} \mathrm{HCl}$. The polymer nanoparticle aqueous dispersion (10 $\mathrm{wt} \%$ at $\mathrm{pH} 7$ ) was gradually dropped to the NR dispersion with gentle mechanical stirring. The polymer composites of NR/PS and $\mathrm{NR} / \mathrm{P}(\mathrm{S}-\mathrm{MAA})$ were obtained when the $\mathrm{pH}$ of the mixture solutions were adjusted to 1 by adding $0.3 \mathrm{M} \mathrm{HCl}$. The blending ratio was determined relating to the theoretical number $\left(N_{\max }\right)$ which is the maximum number of small particles [PS or P(SMAA)] forming a close-packed monolayer on a large particle (NRL) as given by Equation (1) shown below [25]. To investigate the mechanical properties, NR/PS and NR/P(S-MAA) emulsions were

Table 1. Recipes for the preparation of P(S-MAA) and PS particles by emulsifier-free emulsion polymerizations $^{\text {a }}$

\begin{tabular}{|l|c|c|}
\hline \multicolumn{1}{|c|}{ Ingredient } & P(S-MAA) & PS \\
\hline $\mathrm{H}_{2} \mathrm{O}[\mathrm{g}]$ & 270.00 & 290.00 \\
\hline $\mathrm{KPS}[\mathrm{g}]$ & 0.24 & 0.86 \\
\hline $\mathrm{S}[\mathrm{g}]$ & 27.50 & 10.00 \\
\hline MAA $[\mathrm{g}]$ & 2.50 & - \\
\hline
\end{tabular}

a2 $200 \mathrm{rpm}, 70^{\circ} \mathrm{C}, 24 \mathrm{~h}$, purged by $\mathrm{N}_{2}$



Figure 2. Schematic of the heterocoagulation of NRL and polymer nanoparticles dried in vacuum oven at $40^{\circ} \mathrm{C}$ to obtain composite films:

$N_{\max }=\frac{2 \pi}{3} \cdot\left[\frac{R_{\mathrm{L}}+R_{\mathrm{S}}}{R_{\mathrm{S}}}\right]^{2}$

where $R_{\mathrm{L}}$ radius of large particle, $R_{\mathrm{S}}$ radius of small particle.

\subsection{Characterizations}

Particle diameters and zeta potential were measured by dynamic light scattering (DLS; Zetasizer nano ZS, Malvern, USA) at room temperature. Polymer emulsion samples (approximately $10 \mathrm{wt} \%$ ) withdrawn from the reactor were directly measured by concentration mode of DLS. PS and P(S-MAA) particles were observed with transmission electron microscope (TEM; JEM-1230, JEOL Ltd., Japan). Each emulsion was diluted to approximately $50 \mathrm{ppm}$, and then a drop was placed on a carboncoated copper grid before drying at room temperature in a desiccator. Scanning electron microscope (SEM; JSM-6510, JEOL Ltd., Japan) were used to investigate the morphology of the polymer nanocomposite. For SEM observation, one drop of the polymer dispersion was placed on a nickel SEM stub and dried before Au-coating. Tensile test experiments were conducted on a universal testing machine (Instron, 55R4502, S/N H3342, MA, USA) with a cross head speed of $50 \mathrm{~mm} / \mathrm{min}$ and the sample length between the jaws is $65 \mathrm{~mm}$, gauge length $25 \mathrm{~mm}$ and the thickness $2.0 \mathrm{~mm}$. The measurement was done at room temperature.

\section{Results and discussion}

\subsection{Polymer nanoparticles}

PS and P(S-MAA) nanoparticles prepared by emulsifier-free emulsion polymerization were spherical particles as shown in Figure 3. Narrow particle size distribution was obtained for both of them which are characteristic of polymer particles obtained from emulsifier-free emulsion polymerization whereas the presence of emulsifiers results in a broader particle size distribution [26, 27]. In the case of the particle size, PS particles $(500 \mathrm{~nm})$ is much larger than $\mathrm{P}(\mathrm{S}-\mathrm{MAA})(200 \mathrm{~nm})$ as shown in Figure 4. Even though both particles are mainly stabilized with electrostatic repulsion of the sulfate ion generated from KPS initiator, in the case of P(S-MAA), carboxyl group in MAA molecule is also able to stabi- 


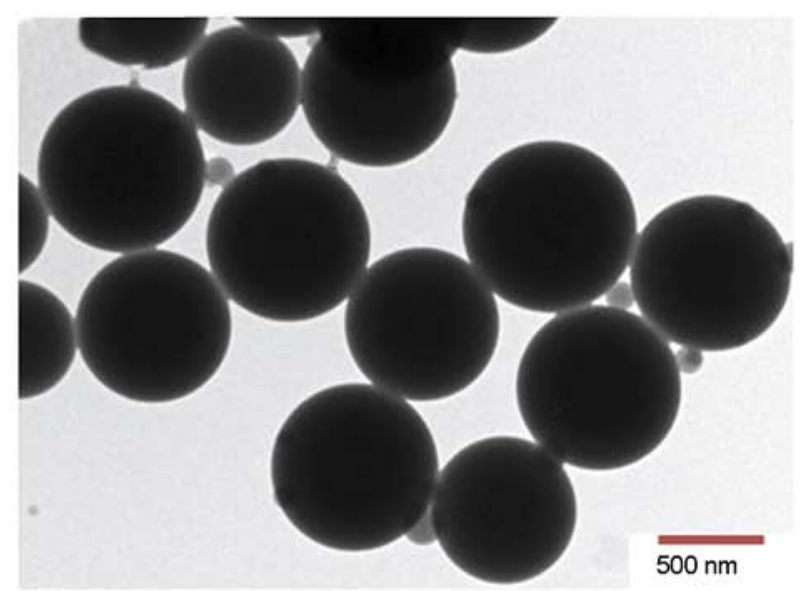

a)

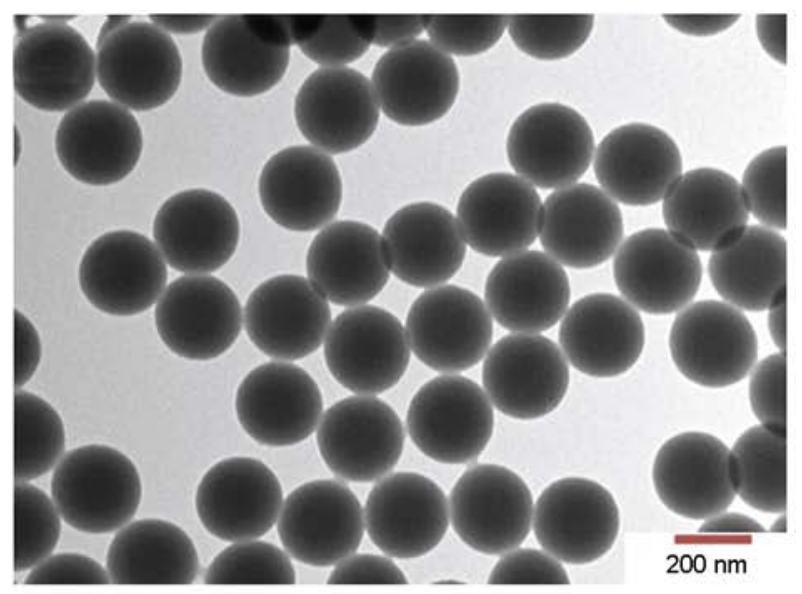

b)

Figure 3. TEM micrographs of polymer nanoparticles prepared by emulsifier-free emulsion polymerizations: (a) PS and (b) P(S-MAA)

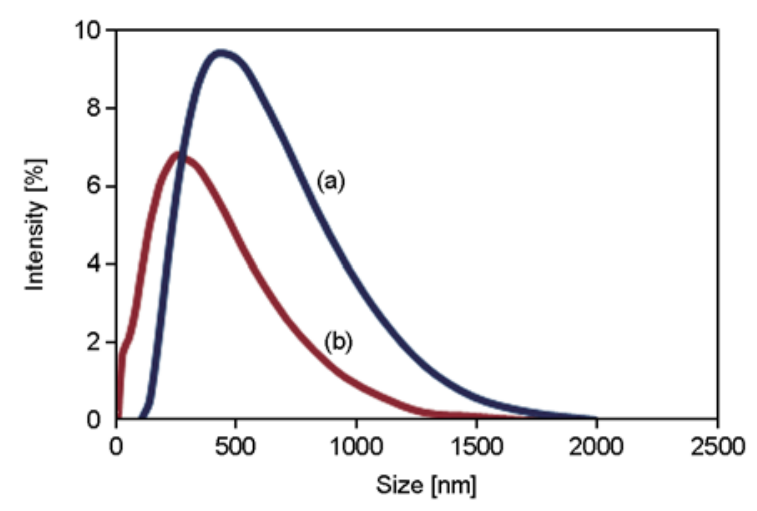

Figure 4. Particle size distribution of polymer nanoparticles prepared by emulsifier-free emulsion polymerizations: (a) PS and (b) P(S-MAA)

lize the particles resulting in the formation of smaller particle than PS.

\subsection{Polymer nanocomposites}

To prepare composite polymer with heterocoagulation technique where the smaller particle is adsorbed on the larger particle using electrostatic interaction, both particle surfaces should have opposite charges.



Figure 5. Particle size distribution of NRL
This technique required the larger particle as core and smaller particle as shell [16]. Although, DLS distribution curve of NRL (Figure 5) giving bimodal peak with the particle size (number-average) of 330 and $1000 \mathrm{~nm}$, NRL was still expected to be the core due to most of NRL weight is the larger size (by weight) while the smaller particles of PS or P(SMAA) was the shell. Due to the presence of negative charge of smaller particles mainly derived from sulfate ion, NRL surface should contain the positive charge in order to achieve the blending.

Generally, NRL surface is covered by protein molecules containing acidic and basic side groups described as carboxyl and amino groups, respectively, showing different charged forms depending on its $\mathrm{pH}$. At the appropriate $\mathrm{pH}$ where the positive and negative charges on NRL surface are balanced, the net charge is zero, called isoelectric point. The net negative charge will be obtained due to deprotonation of more acidic group when the $\mathrm{pH}$ is higher than the isoelectric point. In contrast, if the $\mathrm{pH}$ is lower than its isoelectric point, NRL surface gives net positive charge with the protonation of the more basic group. The charge mechanism of protein adsorbed on the NRL surface is shown in Figure 6.

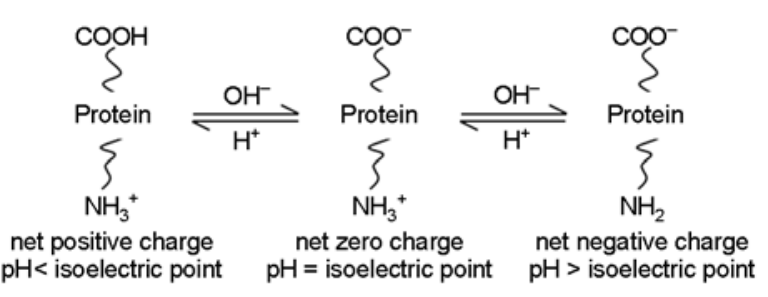

Figure 6. Charge mechanism of protein on the surface of NRL particle 


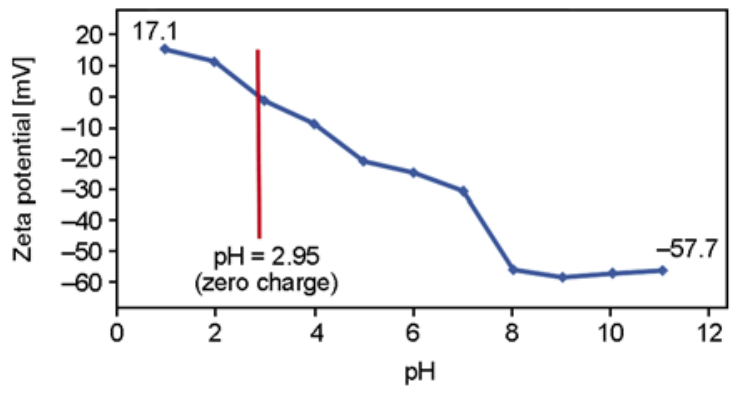

Figure 7. Zeta potential of NRL adsorbed with Tween 80 at various $\mathrm{pH}$

Therefore, NRL surface charge was measured at various $\mathrm{pHs}$ in order to obtain the optimum $\mathrm{pH}$ giving positive charge. Before charge measurement, nonionic emulsifier (Tween 80) was added to NRL emulsion to maintain the colloidal stability of NRL throughout the experiment especially at the $\mathrm{pH}$ giving less charge or neutral. It is well known that Tween 80 contains alcohol, ketone, and ether groups which are able to be protonated under acidic conditions. Therefore, it may increase net positive charge on NRL surface. The zeta potentials of NRL surface at various $\mathrm{pH}$ was shown in Figure 7. It is found that the $\mathrm{pH}$ at the isoelectric point is 2.95 . Therefore, $\mathrm{pH}$ of 1 giving the charge of $+17.1 \mathrm{mV}$ was selected for the blending condition.

In the case of PS and P(S-MAA) nanoparticles, the negative charge on their surfaces at $\mathrm{pH} 1$ measured with zeta potential technique were -35.6 and $-4.3 \mathrm{mV}$ for PS and P(S-MAA), respectively. The difference of the charge between both polymers nanoparticles is due to the utilization of larger amount of KPS for PS than P(S-MAA) preparations. The emulsifier-free emulsion polymerization of less polar monomer as $\mathrm{S}$ needed much amount of ionic initiator to stabilize the polymer particles during polymerization. Moreover, carboxyl group which is the weak acid is not able to ionize in high acidic condition ( $\mathrm{pH}$ 1) resulting in less negative charge of $\mathrm{P}$ (S-MAA).

For the blending of NRL and PS or P(S-MAA), large coagulation was formed when they were directly mixed at the optimum $\mathrm{pH}$. This phenomenon is also observed with the blending of poly(styrene-co-butyl acrylate-co-methacrylic acid) and poly(styrene-co-methacryloyloxy ethyltrimethyl ammonium chloride) [20,21]. To succeed blending, they were mixed at the $\mathrm{pH}$ where their surfaces gave the same charge and then change the $\mathrm{pH}$ to the optimum condition where both polymers show the opposite charge. Therefore, firstly, PS or P(SMAA) emulsion at the Nmax calculated by Equation (1) adjusted $\mathrm{pH}$ to 7 with $1.0 \mathrm{M} \mathrm{NaOH}$ solution was added to NRL emulsion ( $\mathrm{pH} 7$ ) adsorbed with nonionic emulsifier. Secondly, the $\mathrm{pH}$ of the mixing emulsion was adjusted from 7 to 1 where NRL and nanoparticle surfaces act positive and negative charges, respectively. The nanoparticle would gradually adsorb on NRL particles during decreasing of the $\mathrm{pH}$. Finally, the composite polymer (NR/PS or $\mathrm{NR} / \mathrm{P}(\mathrm{S}-\mathrm{MAA})$ ) where NRL particle is core and nanoparticle [PS or P(S-MAA)] is shell dispersed in aqueous medium were obtained. The composite polymer of NR/PS and NR/P(S-MAA) were successfully prepared by heterocoagulation as the particles sizes distribution of the blending dispersions of NRL and polymer nanoparticles (PS: Figure 8 and $\mathrm{P}(\mathrm{S}-\mathrm{MAA})$ : Figure 9) are larger than those of the host NRL. The prepared NR/PS and NR/P(SMAA) composite polymers were observed by SEM as shown in Figure 10. The polymer nanoparticles are adsorbed on NRL as nano-cluster (Figure 10c

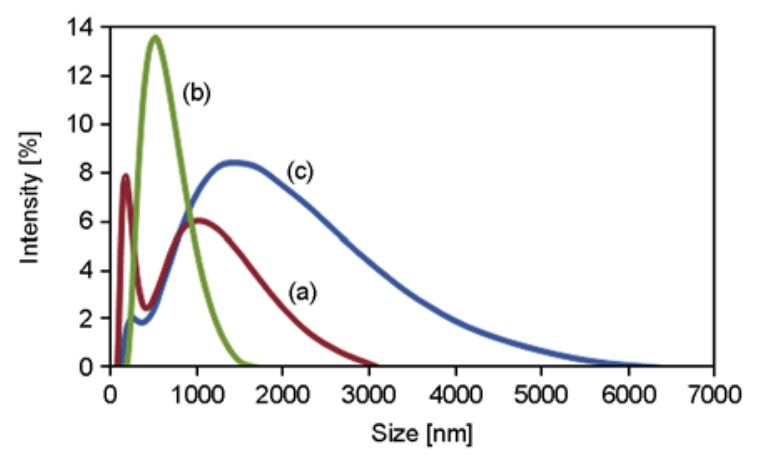

Figure 8. Particle size distributions of NRL (a), PS particle prepared by emulsifier-free emulsion polymerization (b) and NR/PS (c) prepared by heterocoagulation

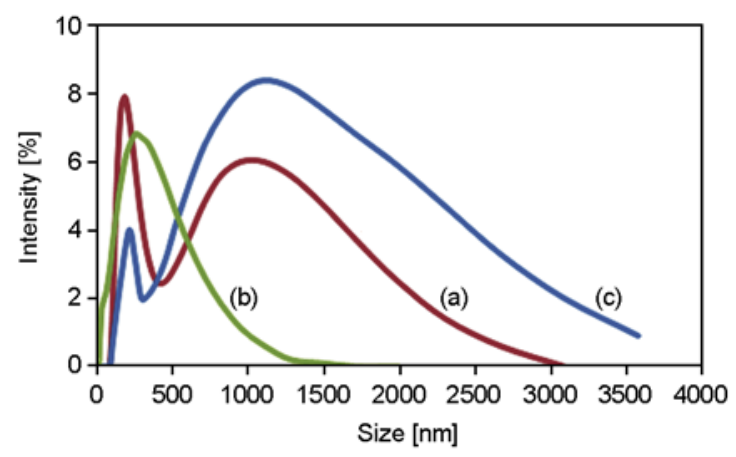

Figure 9. Particle size distributions of NRL (a); P(S-MAA) particle prepared by emulsifier-free emulsion polymerization (b) and NR/P(S-MAA) (c) prepared by heterocoagulation 


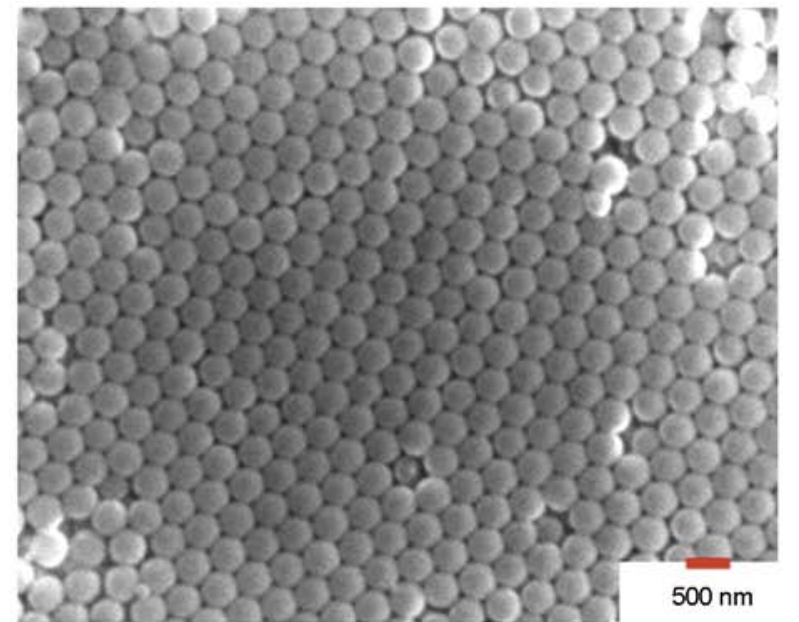

a)

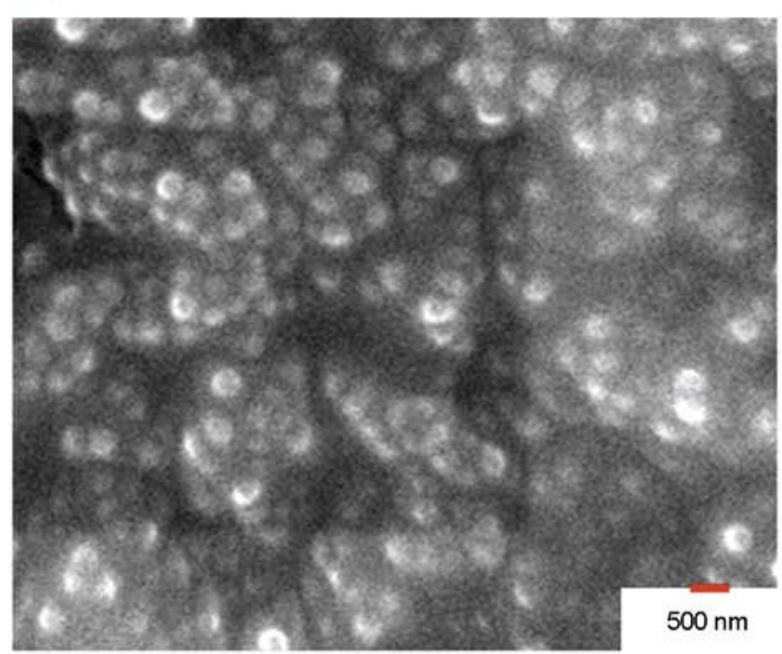

c)

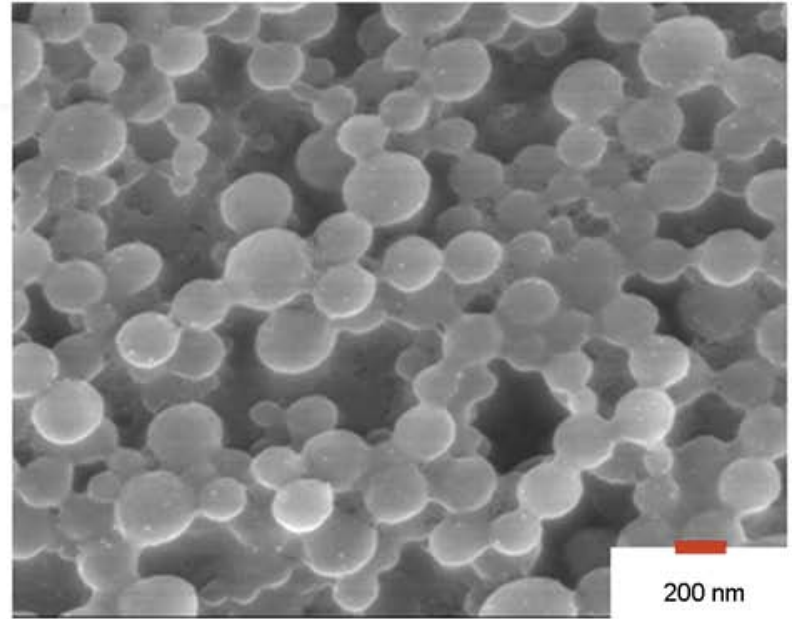

b)

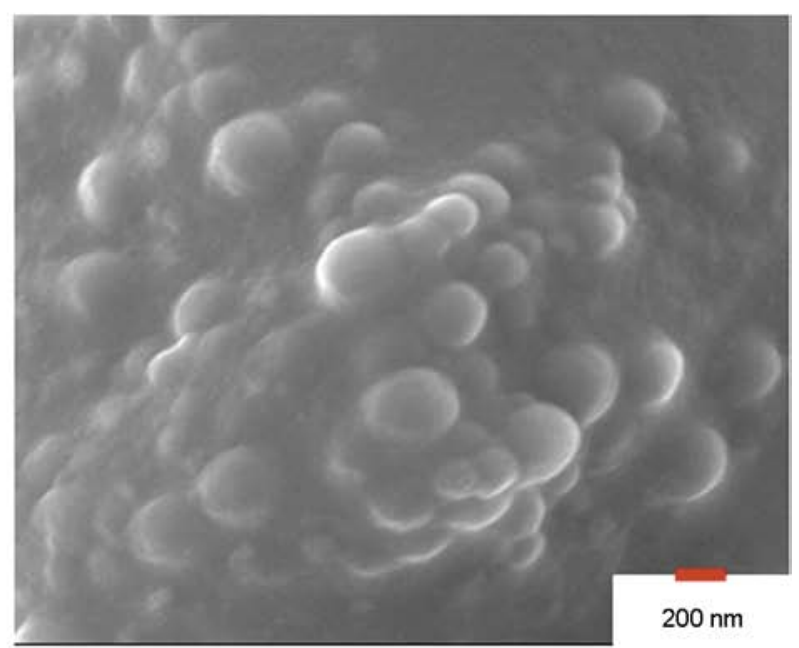

d)

Figure 10. SEM micrographs of PS (a) and P(S-MAA) (b) particles prepared by emulsifier-free emulsion polymerization and NR/PS (c) and NR/P(S-MAA) (d) prepared by heterocoagulation

and 10d). This confirms that NR/PS and NR/P(SMAA) nanocomposites were successfully prepared by heterocoagulation technique.

\subsection{Mechanical properties of polymer nanocomposites}

The mechanical properties of the polymer nanocomposites (NR/PS and NR/P(S-MAA)) were expectedly improved compared with the original NR according to the improvement of NR by incorporation of silica particles [3]. The mechanical properties of the composite films were shown in Table 2. NR film, the elastomeric polymer, shows good elasticity and flexibility as the elongation at break of $796 \%$ and low rigidity as the ultimate tensile strength and modulus of only 0.43 and $0.70 \mathrm{MPa}$, respectively. The ultimate tensile strength and modulus are greatly improved for NR/PS and NR/P(S-
Table 2. Mechanical properties of original NR, NR/PS and NR/P(S-MAA) composites

\begin{tabular}{|l|c|c|c|}
\hline \multicolumn{1}{|c|}{ Samples } & $\begin{array}{c}\text { Ultimate tensile } \\
\text { strenght } \\
{[\mathbf{M P a}]}\end{array}$ & Modulus & $\begin{array}{c}\text { Elongation } \\
\text { at break } \\
{[\mathbf{M P a}]}\end{array}$ \\
\hline $\mathrm{NR}$ & 0.43 & 0.70 & 795.76 \\
\hline $\mathrm{NR} / \mathrm{PS}$ & 3.69 & 594.20 & 2.01 \\
\hline $\mathrm{NR} / \mathrm{P}$ (S-MAA) & 7.05 & 2553.91 & 0.57 \\
\hline
\end{tabular}

MAA) composite films which is affected by the reinforcement of the polymer nanoparticles. However, polymer nanoparticles reduced the film flexibility according to the reduction of their elongation at break because of the limitation in the polymer chain slipping beside the polymer nanoparticle surface. Therefore, for the applications, the amount of polymer nanoparticles should be varied in the heterocoagulation step corresponding to the appropriate mechanical properties. 


\section{Conclusions}

The simple blending as heterocoagulation was successfully applied to produce polymer nanocomposite of NR/PS and NR/P(S-MAA). The polymers were mixed in the dispersed phase with controlling $\mathrm{pH}$ approximately 1 where the surface of NRL giving positive charge and negative charge of polymer nanoparticles surface. The adsorption of polymer nanoparticles on NRL surface took place via electrostatic interaction resulting in the formation of the composite polymer of NR/PS and NR/P(S-MAA). The mechanical properties of the polymer composites remarkably increase compared with the original NR affected from polymer nanoparticles filler. To improve the mechanical properties of polymer composite matched with the applications, it is easily handle by adding the appropriate amount of polymer nanoparticles.

\section{Acknowledgements}

This work was supported by The National Research Council, Thailand (No. 23666).

\section{References}

[1] Kawahara S., Kawazura T., Sawada T., Isono Y.: Preparation and characterization of natural rubber dispersed in nano-matrix. Polymer, 44, 4527-4531 (2003).

DOI: 10.1016/S0032-3861(03)00415-4

[2] Paiphansiri U., Tangboriboonrat P.: Prevulcanisation of skim latex: Morphology and its use in natural rubber based composite material. Colloid and Polymer Science, 284, 251-257 (2005).

DOI: 10.1007/s00396-005-1361-y

[3] Peng Z., Kong L. X., Li S-D., Chen Y., Huang M. F.: Self-assembled natural rubber/silica nanocomposites: Its preparation and characterization. Composites Science and Technology, 67, 3130-3139 (2007).

DOI: 10.1016/j.compscitech.2007.04.016

[4] Kurian J. K., Peethambaran N. R., Mary K. C., Kuriakose B.: Effect of vulcanization systems and antioxidants on discoloration and degradation of natural rubber latex thread under UV radiation. Journal of Applied Polymer Science, 78, 304-310 (2000).

DOI: 10.1002/1097-4628(20001010)78:2<304::AIDAPP100>3.0.CO;2-G

[5] Abad L. V., Relleve L. S., Aranilla C. T., Aliganga A. K., San Diego C. M., dela Rosa A. M.: Natural antioxidants for radiation vulcanization of natural rubber latex. Polymer Degradation and Stability, 76, 275-279 (2002).

DOI: $10.1016 / \mathrm{S} 0141-3910(02) 00024-1$
[6] Ho C. C., Kondo T., Muramatsu N., Ohshima H.: Surface structure of natural rubber latex particles from electrophoretic mobility data. Journal of Colloid and Interface Science, 178, 442-445 (1996).

DOI: $10.1006 /$ jcis. 1996.0139

[7] Busfield J. J. C., Deeprasertkul C., Thomas A. G.: The effect of liquids on the dynamic properties of carbon black filled natural rubber as a function of pre-strain. Polymer, 41, 9219-9225 (2000).

DOI: $10.1016 / \mathrm{S} 0032-3861(00) 00306-2$

[8] Cai H-H., Li S-D., Tian G-R., Wang H-B., Wang J-H.: Reinforcement of natural rubber latex film by ultrafine calcium carbonate. Journal of Applied Polymer Science, 87, 982-985 (2003).

DOI: $10.1002 / a p p .11410$

[9] Arroyo M., López-Manchado M., Herrero B.: Organomontmorillonite as substitute of carbon black in natural rubber compounds. Polymer, 44, 2447-2453 (2003). DOI: 10.1016/S0032-3861(03)00090-9

[10] Teh P. L., Mohd Ishak Z. A., Hashim A. S., KargerKocsis J., Ishiaku U. S.: Effects of epoxidized natural rubber as a compatibilizer in melt compounded natural rubber-organoclay nanocomposites. European Polymer Journal, 40, 2513-2521 (2004).

DOI: 10.1016/j.eurpolymj.2004.06.025

[11] Lu Y-L., Ye F-Y., Mao L-X., Li Y., Zhang L-Q.: Microstructural evolution of rubber/clay nanocomposites with vulcanization process. Express Polymer Letters, 5, 777-787 (2011).

DOI: $10.3144 /$ expresspolymlett.2011.76

[12] Varghese S., Karger-Kocsis J.: Natural rubber-based nanocomposites by latex compounding with layered silicates. Polymer, 44, 4921-4927 (2003). DOI: 10.1016/S0032-3861(03)00480-4

[13] Magaraphan R., Thaijaroen W., Lim-ochakun R.: Structure and properties of natural rubber and modified montmorillonite nanocomposites. Rubber Chemistry and Technology, 76, 406-418 (2003). DOI: $10.5254 / 1.3547751$

[14] Nair K., Dufresne A.: Crab shell chitin whisker reinforced natural rubber nanocomposites. 2. Mechanical behavior. Biomacromolecules, 4, 666-674 (2003).

DOI: $10.1021 / \mathrm{bm} 0201284$

[15] Xu S. H., Gu J., Luo Y. F., Jia D. M.: Effects of partial replacement of silica with surface modified nanocrystalline cellulose on properties of natural rubber nanocomposites. Express Polymer Letters, 6, 14-25 (2012). DOI: $10.3144 /$ expresspolymlett.2012.3

[16] Teixeira R. F. A., Bon S. A. F.: Physical methods for the preparation of hybrid nanocomposite polymer latex particles. Advances in Polymer Science, 233, 19-52 (2010). DOI: $10.1007 / 12201065$

[17] Han J., Kumacheva E.: Monodispersed silica-titanyl sulfate microspheres. Langmuir, 17, 7912-7917 (2001). DOI: $10.1021 / 1 \mathrm{a} 010745 \mathrm{y}$ 
[18] Fleming M. S., Mandal T. K., Walt D. R.: Nanosphere-microsphere assembly: Methods for core-shell materials preparation. Chemistry of Materials, 13, 2210-2216 (2001).

DOI: $10.1021 / \mathrm{cm} 010168 \mathrm{z}$

[19] Taniguchi T., Ogawa T., Kamata Y., Kobaru S., Takeuchi N., Kohri M., Nakahira T., Wakiya T.: Preparation of core-shell coagulates by hydrophobic heterocoagulation of micron-sized poly(methyl methacrylate) and submicron-sized poly(styrene) particles. Colloids and Surfaces A: Physicochemical and Engineering Aspects, 356, 169-175 (2010). DOI: $10.1016 /$ j.colsurfa.2010.01.015

[20] Okubo M., Lu Y., Wang Z.: Production of soft core/ hard shell composite polymer particles by the stepwise heterocoagulation method with heat treatment. Colloid and Polymer Science, 276, 833-837 (1998).

DOI: $10.1007 / \mathrm{s} 003960050317$

[21] Okubo M., Lu Y.: Estimation of surface morphology of composite polymer particles prepared by the stepwise heterocoagulation method with $\zeta$-potential measurement. Colloid and Polymer Science, 276, 282-285 (1998). DOI: $10.1007 / \mathrm{s} 003960050241$

[22] Li G., Yang X., Wang J.: Raspberry-like polymer composite particles via electrostatic heterocoagulation. Colloids and Surfaces A: Physicochemical and Engineering Aspects, 322, 192-198 (2008).

DOI: $10.1016 /$ j.colsurfa.2008.03.006
[23] Kim J. S., Yun J. H., Kim I., Shim S. E.: Electrical properties of graphene/SBR nanocomposite prepared by latex heterocoagulation process at room temperature. Industrial and Engineering Chemistry, 17, 325-330 (2011). DOI: $10.1016 /$ j.jiec.2011.02.034

[24] Sanguansap K., Suteewong T., Saendee P., Buranabunya U., Tangboriboonrat P.: Composite natural rubber based latex particles: A novel approach. Polymer, 46, 1373-1378 (2005).

DOI: 10.1016/j.polymer.2004.11.074

[25] Okubo M., He Y., Ichikawa K.: Analysis of 'stepwise' heterocoagulation process of small cationic polymer particles onto large anionic polymer particles using dynamic light scattering. Colloid and Polymer Science, 269, 125-130 (1991). DOI: $10.1007 / \mathrm{BF} 00660301$

[26] Okubo M., Chaiyasat A., Yamada M., Suzuki T., Kobayashi H.: Influence of hydrophilic-lipophilic balance of nonionic emulsifiers on emulsion copolymerization of styrene and methacrylic acid. Colloid and Polymer Science, 285, 1755-1761 (2007).

DOI: $10.1007 / \mathrm{s} 00396-007-1770-1$

[27] Chaiyasat A., Yamada M., Kobayashi H., Suzuki T., Okubo M.: Incorporation of nonionic emulsifiers inside styrene-methacrylic acid copolymer particles prepared by emulsion copolymerization. Polymer, 49, 3042-3047 (2008).

DOI: $10.1016 /$ j.polymer.2008.05.007 